Check for updates

Cite this: RSC Adv., 2020, 10, 17486

Received 3rd April 2020

Accepted 30th April 2020

DOI: $10.1039 / \mathrm{d}$ Ora03006f

rsc.li/rsc-advances

\section{Simple organocatalyst component system for asymmetric hetero Diels-Alder reaction of isatins with enones $\uparrow$}

\author{
Perumalsamy Parasuraman, ${ }^{a}$ Zubeda Begum, ${ }^{a}$ Madhu Chennapuram, ${ }^{a}$ Chigusa Seki, ${ }^{a}$ \\ Yuko Okuyama, ${ }^{\text {b }}$ Eunsang Kwon, ${ }^{c}$ Koji Uwai, ${ }^{a}$ Michio Tokiwa, ${ }^{d}$ Suguru Tokiwa, ${ }^{d}$ \\ Mitsuhiro Takeshita ${ }^{d}$ and Hiroto Nakano (D) *a
}

A simple two catalyst component system consisting of primary $\beta$-amino alcohols as a catalyst and amino acids as a co-catalyst put together works as an efficient organocatalyst system in the hetero Diels-Alder reaction of isatins with enones to afford the chiral spirooxindole-tetrahydropyranones in good chemical yields and stereoselectivities (up to $86 \%$, up to 85 : $15 \mathrm{dr}$., up to $95 \%$ ee).

\section{Introduction}

Spirooxindoles A are considered to be promising scaffolds in drug discovery. ${ }^{1}$ The structure of $\mathbf{A}$ is contained in many compounds having pharmacological activities such as contraceptive ${ }^{2}$ anti-HIV ${ }^{3}$ anticancer, ${ }^{4}$ antituberculosis, ${ }^{5}$ antimalarial, ${ }^{6}$ and antiproliferative drugs. ${ }^{9}$ Therefore, the development of an effective strategy for the preparation of highly optically pure spirooxindole $\mathbf{Z}$ is a significantly challenging task in research. ${ }^{1}$ The hetero Diels-Alder (HDA) reaction is a versatile tool for effectively forming heterocyclic compounds. ${ }^{7}$ Especially, the catalytic asymmetric version of this reaction is the most efficient and convenient method for constructing a chiral heterocyclic skeleton, which acts as a precursor for many biologically active compounds and drugs. ${ }^{8}$ In this class of HDA reactions, the reaction of isatins $\mathbf{X}$ with enones $\mathbf{Y}$ is one of the superior organic transformations for providing unique chiral spirooxindole-tetrahydropyranones $\mathbf{Z}$ containing quaternary chiral carbon center on the structure (Scheme 1). ${ }^{9}$ Most recently, Tanaka and co-workers have reported an efficient organocatalyzed asymmetric HDA reaction of $\mathbf{X}$ with $\mathbf{Y}$ using three catalysts component system being composed with chiral amine as a catalyst, amino acid and thiourea as co-catalysts for affording Spirooxindole $\mathbf{Z}$ with satisfactory chemical yield and stereoselectivity (Scheme 1). ${ }^{9} \quad$ However, the favourable

${ }^{a}$ Division of Sustainable and Environmental Engineering, Graduate School of Engineering, Muroran Institute of Technology, 27-1 Mizumoto-cho, Muroran 050-8585, Japan. E-mail: catanaka@mmm.muroran-it.ac.jp

${ }^{b}$ Tohoku Medical and Pharmaceutical University, 4-4-1 Komatsushima, Aoba-Ku, Sendai 981-8558, Japan

${ }^{c}$ Research and Analytical Center for Giant Molecules, Graduate School of Sciences, Tohoku University, 6-3 Aoba, Aramaki, Aoba-Ku, Sendai 980-8578, Japan

${ }^{d}$ Tokiwakai Group, 62 Numajiri Tsuduri-Chou Uchigo, Iwaki 973-8053, Japan

$\uparrow$ Electronic supplementary information (ESI) available: Experimental details and HPLC data. See DOI: 10.1039/d0ra03006f geometric combination of three catalysts system of complex chiral cinchona alkaloid $\mathbf{A}$ as a catalyst and both the prepared complex chiral amino acids $\mathbf{B}$ and thioureas $\mathbf{C}$ as co-catalysts require time and effort for controlling the enantioselective reaction course for obtaining satisfactory chemical yield and stereoselectivity. Therefore, the development of a more convenient and easier catalytic component system for this versatile reaction is deeply required significantly.

Based on these backgrounds, we have designed a simple two catalysts component system for this reaction (Scheme 1). About the catalysts system, we focused on a concept of the combination of simple $\beta$-amino alcohol $\mathbf{D}$ as an organocatalyst for the generation of a diene species and common simple amino acid $\mathbf{E}$ as a co-catalyst for the activation of isatin substrate acting as

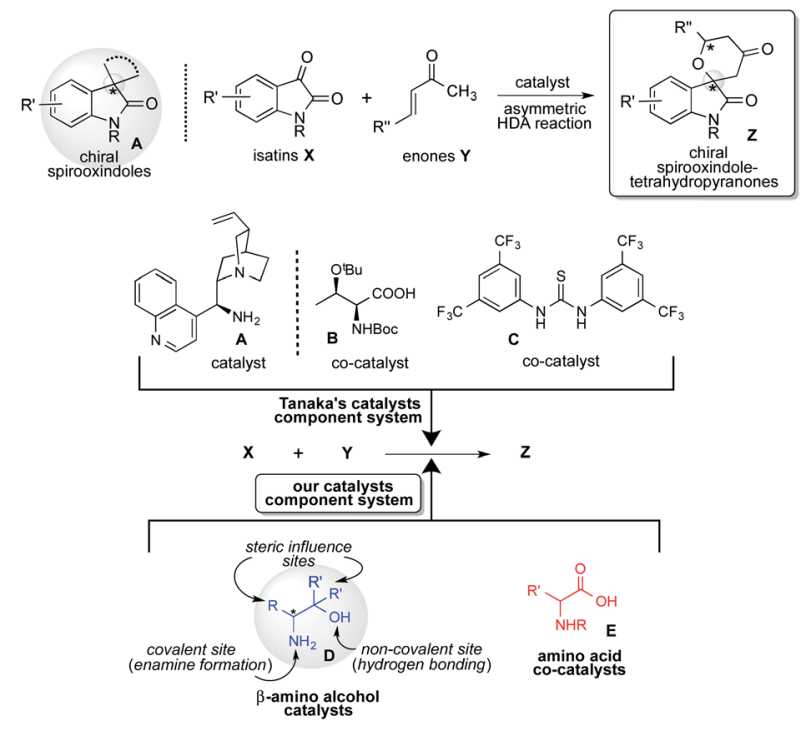

Scheme 1 Asymmetric HDA reaction of isatins with enones using catalysts component system. 


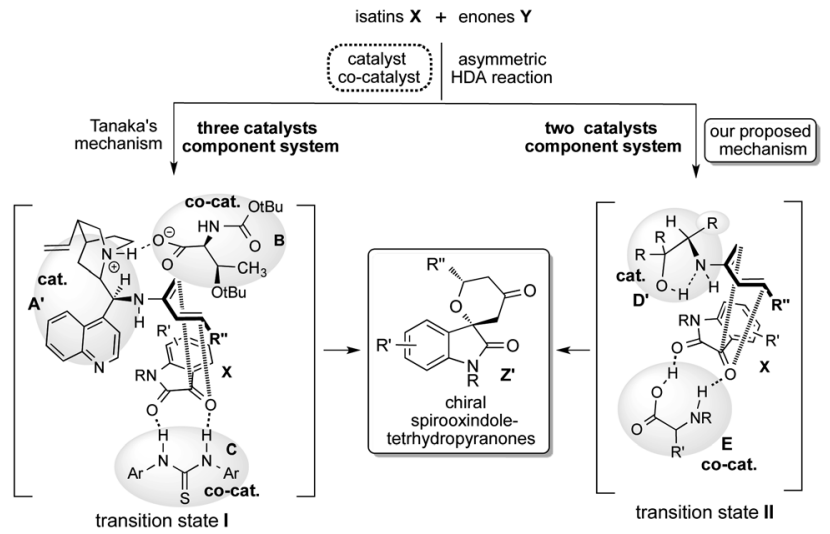

Scheme 2 Concept of our two catalysts component system.

a dienophile comparatively to the complex catalyst system of Tanaka and co-workers having one catalyst and two co-catalysts. Recently, we have reported that simple $\beta$-amino alcohols $\mathbf{D}$ and their derivatives work as an efficient organocatalyst in various asymmetric reactions..$^{10}$ As an advantage of catalyst $\mathbf{D}$, it can be easily prepared from commercially available amino acids in a single step and also contains the primary amino group as covalent site, hydroxyl group as a non-covalent site and steric influence site in the single molecule (Scheme 2). Furthermore, simple amino acids as co-catalyst are commercially available. Therefore, combined these properties of amino alcohols as a catalyst and amino acids as a co-catalyst may enable the formation of a simple catalytic component system. This organocatalysed asymmetric HDA reaction might proceed via transition state II (comparing to Tanaka's proposed reaction course $\mathbf{I}^{9}{ }^{9}$ in which the diene species $\mathbf{D}^{\prime}$ is formed by the reaction of primary amino group on catalyst $\mathbf{D}$ with enones $\mathbf{Y}$, and then isatin dienophile $\mathbf{X}$ is activated by amino acids co-catalyst $\mathbf{E}$ by the two points of hydrogen bonding interactions (Scheme 2). In this transition state II, diene species $\mathbf{D}^{\prime}$ might attack stereoselectively from less sterically hindered site of the incoming generated dienes to afford the chiral spirooxindoles $\mathbf{Z}$.

Herein, we describe a simple two catalysts component system, primary $\beta$-amino alcohols $\mathbf{D}$ having only one chiral carbon center on the molecule as a catalyst and simple nonchiral $\mathrm{N}$-protected amino acids $\mathbf{E}$ as a co-catalyst, together acts as an efficient component organocatalysts system in the HDA reaction of $\mathbf{X}$ with $\mathbf{Y}$ to afford the chiral $\mathbf{Z}$ in good chemical yields (up to $86 \%$ ) and with excellent stereoselectivities (up to 85 : 15 dr., $95 \%$ ee).

\section{Results and discussion}

\subsection{Preparations of catalysts $2 a-e$ and $4 a-e$}

$\beta$-Amino alcohol organocatalysts $2 \mathbf{a}-\mathbf{e}$ and $4 a-\mathbf{e}$ were easily prepared by the reductions of the corresponding amino acids 1a-e and Grignard reactions of the corresponding amino esters 3a-e, respectively (Table 1). ${ }^{10 a}$ Furthermore, $N$-Cbz- and $N$-Boc-amino acids $\mathbf{5 b}-\mathbf{g}$ as co-catalyst were also easily derived from the corresponding commercially available non-protected amino acids.

\subsection{Screening of catalysts $2 a-e$ and $4 a-e$}

Firstly, we examined the HDA reaction of isatin $\mathbf{6 a}$ as a dienophile with heptene-2-one $7 \mathbf{a}$ as a diene source, using only amino alcohol organocatalysts $2 \mathrm{a}$ with primary hydroxyl methyl or $\mathbf{4 a}$ with bulkier hydroxyl diphenylmethyl groups (entries 1 and 2, Table 1). The reaction was carried out with catalysts $2 \mathrm{a}$ or $4 \mathrm{a}$ in toluene at room temperature for $48 \mathrm{~h}$ for comparison with the catalytic efficiency of three catalysts component system by Tanaka and co-workers. ${ }^{9}$ Simple amino alcohol 2a showed good catalytic activity in this reaction and the corresponding HDA adduct $\left[2^{\prime} S, 6^{\prime} R\right]-8 \mathbf{a}$ was obtained in excellent enantioselectivity ( $92 \%$ ee) and with good diastereoselectivity $(85: 15)$, although the chemical yield was extremely low (15\%) (entry 1). On the other hand, the use of bulkier amino alcohol catalyst 4a did not show catalytic activity in this reaction condition (entry 2). These results deeply suggested the necessity of co-catalyst for the activation of isatin dienophile, and also the structure of amino alcohol catalyst may be important for showing a good catalytic activity.

Just in case, the catalytic activity of amino acid 1a (L-tertleucine) with the primary amino group for generating diene species was also examined under the same reaction condition (entry 3). However, its catalytic activity was not confirmed at all, for a reason that neutral amino acids exist in betaine form which might not work for the generation of the diene species. The most curious thing is that enantioselectivity was controlled almost completely ( $92 \%$ ee) to afford the HDA adduct 8a using simple small $\beta$-amino alcohol molecules independently. Thus, amino alcohol alone worked as a catalyst for almost completely shielding one side of the enantiotopic face when diene attack to dienophile. These results indicated the necessity of our two catalysts component system comprising of amino alcohol catalyst for generating diene species and for controlling stereoselective reaction course and amino acid co-catalyst for activating isatin dienophile. Based on the results in entries 1 and 3 , we next examined this reaction using the combinations of catalyst $2 \mathbf{a}(20 \mathrm{~mol} \%)$ with amino acids $\mathbf{5 a - g}$ or common organic acids $\mathbf{5 h}-\mathbf{j}$ as co-catalysts $(40 \mathrm{~mol} \%)$ at room temperature for $48 \mathrm{~h}$ (entries 4-13). First, the reaction using the simplest amino acid 5a having free amino group as a co-catalyst was carried out in the presence of catalyst $2 a$ (entry 4). Contrary to expectation, neutral acid $\mathbf{5 a}$, which hardly worked as co-catalyst for activating of isatin dienophile $7 \mathrm{a}$, showed excellent enantioselectivity $(95 \%$ ee) with good diastereoselectivity, although chemical yield was quite low ( $14 \%$ ee). Interestingly, the use of 2a and 5a combined together increased the enantioselectivity ( $95 \%$ ee) then the result ( $92 \%$ ee) of the independently use of amino alcohol 2a (entry 1). Amino acid 5a might act as steric factor for controlling the attacking direction of diene to afford 8a with superior enantioselectivity. Next, we tried the combinations of superior catalyst 2a with other $N$-protected amino acids $\mathbf{5 b} \mathbf{b} \mathbf{g}$ or common organic acids $\mathbf{5 h} \mathbf{h} \mathbf{j}$ as co-catalysts in this reaction condition (entries 5-13). All of co-catalysts $5 \mathbf{b}-\mathbf{g}$ assisted the progress of the reaction for affording chiral 8a with moderate to good results. Especially, highly satisfactory results for chemical yields and stereoselectivities were obtained when 


\begin{tabular}{|c|c|c|c|c|c|c|c|}
\hline Entry & Enone 7a, (eq.) & Cat. $2 \mathbf{a}-\mathbf{e}, \mathbf{4 a}-\mathbf{e}(\mathrm{mol} \%)$ & Co-cat. 5a-k (mol\%) & Temp. $\left({ }^{\circ} \mathrm{C}\right)$ & Yield $^{a}(\%)$ & $\mathrm{dr}^{b}$ & $\operatorname{Ee}^{c}(\%)$ \\
\hline 1 & 4 & $2 \mathbf{a}(20)$ & - & $\mathrm{rt}$ & 15 & 8515 & 92 \\
\hline 2 & 4 & $4 a(20)$ & - & $\mathrm{rt}$ & trace & - & - \\
\hline 3 & 4 & 1a $(20)$ & - & $\mathrm{rt}$ & - & - & - \\
\hline 4 & 4 & $2 a(20)$ & $\mathbf{a}(40)$ & $\mathrm{rt}$ & 14 & 7525 & 95 \\
\hline 5 & 4 & $2 a(20)$ & b (40) & $\mathrm{rt}$ & 80 & 7921 & 91 \\
\hline 6 & 4 & $2 a(20)$ & c (40) & $\mathrm{rt}$ & 86 & 8020 & 92 \\
\hline 7 & 4 & $2 a(20)$ & d (40) & $\mathrm{rt}$ & 61 & 8218 & 88 \\
\hline 8 & 4 & $2 a(20)$ & e (40) & $\mathrm{rt}$ & 87 & 8119 & 87 \\
\hline 9 & 4 & $2 a(20)$ & $\mathbf{f}(40)$ & $\mathrm{rt}$ & 90 & 8218 & 88 \\
\hline 10 & 4 & $2 a(20)$ & $\mathbf{g}(40)$ & $\mathrm{rt}$ & 97 & 7525 & 84 \\
\hline 11 & 4 & $2 a(20)$ & h $(40)$ & $\mathrm{rt}$ & 68 & 7525 & 86 \\
\hline 12 & 4 & $2 a(20)$ & i (40) & $\mathrm{rt}$ & 68 & 8416 & 87 \\
\hline 13 & 4 & $2 a(20)$ & $\mathbf{j}(40)$ & $\mathrm{rt}$ & tra & - & - \\
\hline 14 & 4 & $2 a(20)$ & k (40) & $\mathrm{rt}$ & 19 & 7327 & 75 \\
\hline 15 & 4 & $2 \mathbf{b}(20)$ & c (40) & $\mathrm{rt}$ & 16 & 7525 & 86 \\
\hline 16 & 4 & $2 \mathrm{c}(20)$ & c (40) & $\mathrm{rt}$ & 66 & 5545 & 72 \\
\hline 17 & 4 & $2 d(20)$ & c (40) & $\mathrm{rt}$ & 78 & 6436 & 81 \\
\hline 18 & 4 & $2 \mathrm{e}(20)$ & c (40) & $\mathrm{rt}$ & 61 & 5050 & 88 \\
\hline 19 & 4 & $4 \mathbf{b}(20)$ & c (40) & $\mathrm{rt}$ & 14 & 7525 & 24 \\
\hline 20 & 4 & $4 c(20)$ & c (40) & $\mathrm{rt}$ & 18 & 7426 & 41 \\
\hline 21 & 4 & 4d (20) & c (40) & $\mathrm{rt}$ & 28 & 8317 & 14 \\
\hline 22 & 4 & $4 e(20)$ & c (40) & $\mathrm{rt}$ & 24 & 7822 & 6 \\
\hline 23 & 2 & $2 a(20)$ & c (40) & $\mathrm{rt}$ & 47 & 7723 & 90 \\
\hline 24 & 1 & $2 a(20)$ & c (40) & $\mathrm{rt}$ & 17 & 7327 & 89 \\
\hline 25 & 4 & $2 a(20)$ & c (40) & 0 & 56 & 8119 & 93 \\
\hline 26 & 4 & $2 \mathrm{a}(20)$ & c (20) & $\mathrm{rt}$ & 54 & 7822 & 89 \\
\hline 27 & 4 & $2 a(20)$ & c (10) & $\mathrm{rt}$ & 52 & 7921 & 87 \\
\hline 28 & 4 & 2a (10) & c (10) & $\mathrm{rt}$ & 54 & 77822 & 89 \\
\hline 29 & 4 & $2 a(10)$ & c (20) & $\mathrm{rt}$ & 60 & 88119 & 89 \\
\hline 30 & 4 & 2a (10) & c (5) & $\mathrm{rt}$ & 52 & 7921 & 87 \\
\hline
\end{tabular}

${ }^{a}$ Isolated yield. ${ }^{b}$ Diastereoselectivity (dr) was determined by ${ }^{1} \mathrm{HNMR}$ of the crude reaction mixture (major diastereomer: 8a). ${ }^{c}$ The ee value were determined by HPLC (Daicel chiralpak IB column).

the reactions were carried out in the presence of simple nonchiral amino acids, $N$-Cbz-protected $\mathbf{5 b}$ and $N$-Boc-protected $5 \mathbf{c}$ with good chemical yields and stereoselectivities (5b: 80\%, 79 : 21 dr., 91\% ee, 5c: $86 \%, 80: 20,92 \%$ ee) (entries 5 and 6). On the other hand, the uses of common organic acids $5 \mathbf{h}, \mathbf{i}$ brought about the decrease of chemical yield, even though good stereoselectivities were obtained (entries 11 and 12). Furthermore, strongest trifluoro acetic acid (TFA) $\mathbf{5 j}$ did not work as a co-catalyst in this reaction condition (entry 13). Moreover, thioureas 5k that was used as co-catalyst in Tanaka's three catalysts component system ${ }^{9}$ was also applied with amino alcohol organocatalyst $\mathbf{2 a}$ in this reaction. However, this component system of $\mathbf{2 a}$ and $\mathbf{5 k}$ did not work effectively in this reaction (19\%, $73: 27 \mathrm{dr}$., $75 \%$ ee) (entry 14). In addition, three catalysts component system of catalyst $2 \mathrm{a}$ and co-catalysts of both amino acid $\mathbf{5 c}$ and thiourea $\mathbf{5 k}$ also did not show better catalytic activity $(85 \%, 75: 25 \mathrm{dr}$., $82 \%$ ee) than two catalysts component system of $2 \mathbf{a}$ and $\mathbf{5 c}(86 \%, 80: 20 \mathrm{dr}$., $92 \%$ ee). We next examined the reaction of $\mathbf{6 a}$ with $7 \mathbf{a}$ in the presence of $\beta$ amino alcohols $\mathbf{2 b}-\mathbf{e}$ (20 mol\%) as catalysts along with superior simple non-chiral $N$-Boc-amino acid $\mathbf{5 c}$, as a co-catalyst (40 mol\%) in this reaction condition (entries 15-18). Although, all catalysts combination systems, of catalysts $2 \mathbf{b}-\mathbf{e}$ and co-catalyst $\mathbf{5 c}$ showed good catalytic activities to afford the HDA adduct 8a with moderate to good chemical yields, diastereoselectivities and enantioselectivities, but showed inferior results compared to catalyst $\mathbf{2 a}$ and co-catalyst $\mathbf{5 c}$ (entry 6). Moreover, the utility of combination of the catalysts bulkier 
amino alcohol catalysts $\mathbf{4 a - e}$ and superior simplest non-chiral $\mathrm{N}$-Boc-amino acid co-catalyst $\mathbf{5 c}$ were also examined in this reaction condition (entries 19-22). However, better catalytic activities were not confirmed at all than that of the combination of simple catalysts $\mathbf{2 a - e}$ with aprimary hydroxyl group and $\mathbf{5 c}$ (entry 6). From these results, it was revealed that the best catalyst combination was $\beta$-amino alcohols 2 a with primary hydroxyl group as a catalyst and non-chiral $N$-Boc-amino acid as a co-catalyst 5c. Next, the ratio of substrate amounts $6 \mathbf{a}$ and $7 \mathbf{a}$ $(\mathbf{6 a}: 7 \mathbf{a}=1: 2$ and $\mathbf{6 a}: 7 \mathbf{a}=1: 1)$ were examined in the presence of optimised $\mathbf{2 a}$ and co-catalyst $\mathbf{5 c}$ under same reaction condition (entries 23 and 24). However, these results displayed considerable decrease in chemical yields and the reaction temperature performed at $0{ }^{\circ} \mathrm{C}$ also showed a large decrease in chemical yield up to $56 \%$ (entry 25). Next, we examined the molar ratio of catalyst $2 \mathbf{a}$ and co-catalyst $5 \mathbf{c}$ in this reaction of $6 \mathbf{a}$ with 7a (4 equiv.) at room temperature (entries 26-30). Satisfactory enantioselectivities and diastereoselectivities were confirmed under all of the molar ratios of $\mathbf{2 a}$ and $\mathbf{5 c}$. However, chemical yields comparatively decreased when the reaction was carried out under the molar ratio of $20 \mathrm{~mol} \%$ of catalyst $2 \mathrm{a}$ and $40 \mathrm{~mol} \%$ of co-catalyst 5c (entry 6).

We also examined the effects of various solvents and the reaction times to this reaction with an optimized catalyst combination of $2 \mathbf{a}(20 \mathrm{~mol} \%)$ and $5 \mathbf{c}(40 \mathrm{~mol} \%)$ at room temperature (Table 2). As a result, aromatic solvents performed better giving satisfactory chemical yields and stereoselectivities (entries 1-3). Particularly, toluene was found to be effective in

Table 2 Solvent screening for HDA reaction

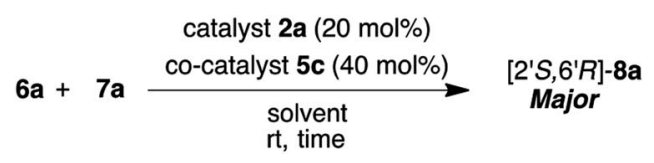

\begin{tabular}{|c|c|c|c|c|c|}
\hline Entry & Solvent & Time (h) & Yield $^{a}(\%)$ & $\mathrm{dr}^{b}$ & $\mathrm{Ee}^{c}(\%)$ \\
\hline 1 & Toluene & 48 & 86 & 8020 & 92 \\
\hline 2 & Benzene & 48 & 60 & 7822 & 90 \\
\hline 3 & Xylene & 48 & 73 & 7723 & 88 \\
\hline 4 & Cyclohexane & 48 & 66 & 7426 & 89 \\
\hline 5 & Hexane & 48 & trace & - & - \\
\hline 6 & $\mathrm{Et}_{2} \mathrm{O}$ & 48 & 55 & 7822 & 90 \\
\hline 7 & $\mathrm{iPr}_{2} \mathrm{O}$ & 48 & 68 & 7723 & 89 \\
\hline 8 & $\mathrm{THF}$ & 48 & 40 & 7921 & 82 \\
\hline 9 & $\mathrm{CH}_{2} \mathrm{Cl}_{2}$ & 48 & 74 & 7921 & 90 \\
\hline 10 & $\mathrm{CHCl}_{3}$ & 48 & 34 & 8416 & 92 \\
\hline 11 & $\mathrm{C}_{2} \mathrm{H}_{4} \mathrm{Cl}_{2}$ & 48 & 75 & 7723 & 88 \\
\hline 12 & $\mathrm{CH}_{3} \mathrm{CN}$ & 48 & 70 & 7525 & 88 \\
\hline 13 & $\mathrm{MeOH}$ & 48 & 38 & 6832 & 83 \\
\hline 14 & Toluene & 24 & 73 & 7921 & 90 \\
\hline 15 & Toluene & 72 & 86 & 7822 & 86 \\
\hline 16 & Toluene & 96 & 78 & 7822 & 86 \\
\hline 17 & Neat & 24 & 87 & 7129 & 86 \\
\hline 18 & Neat & 48 & 75 & 6832 & 82 \\
\hline
\end{tabular}

${ }^{a}$ Isolated yield. ${ }^{b}$ Diastereoselectivity (dr) was determined by ${ }^{1}$ HNMR of the crude reaction mixture (major diastereomer: 8a). ${ }^{c}$ The ee value were determined by HPLC (Daicel chiralpak IB column). this reaction (entry 1). Furthermore, no significant improvement in chemical yields and stereoselectivities was observed when the reaction times were shortened for $24 \mathrm{~h}$ and prolonged for $72 \mathrm{~h}$ and $96 \mathrm{~h}$, respectively (entries 14-16). From these results, it was revealed that the catalyst combination of simple catalyst 2 a $(20 \mathrm{~mol} \%)$ and simple non-chiral $N$-Boc-glycine 5 c (40 mol\%), toluene as solvent, room temperature and $48 \mathrm{~h}$ reaction time was best reaction condition for this reaction. This reaction using three catalysts component system by Tanaka and co-workers mainly afforded HDA adduct 8a which was obtained by concerted HDA cycloaddition, while this reaction also slightly afforded aldol product 9 which is obtained by aldol reaction as a by-product. Similarly, our catalysts component system also slightly afforded similar aldol product 9 in low chemical yield (12\%) and stereoselectivities (72:28 dr, 16\% ee) like Tanaka and co-workers. ${ }^{9}$

\subsection{Substrate scope}

After optimizing the reaction conditions, we examined the generality of the developed superior two catalysts component system of $\mathbf{2 a}$ and $\mathbf{5} \mathbf{c}$ in the reactions of different isatins $\mathbf{6 a - f}$ with enones 7a-e (Scheme 3). This system also showed better catalytic activity in the reactions and afforded the corresponding chiral spirooxindole-tetrahydropyranones $\mathbf{8 b}-\mathbf{j}$ in good to excellent stereoselectivities with moderate to good chemical yields, except the result from the reaction of $\mathbf{6 a}$ with $7 \mathbf{e}$ to did not afford the adduct $\mathbf{8 j}$. From the results, it is strongly indicated that our simple two catalysts component system works effectively in this reaction using variety of substrates.

We also examined this reaction using a large amount of substrate (6a: $1 \mathrm{~g}$, 7a: $3.05 \mathrm{~g}$ ) to demonstrate the practically utility of the two component system in best reaction condition. As a result, the HDA adduct 8a was successfully obtained with $87 \%$ chemical yield with good stereoselectivites $(\mathrm{dr}=80: 20$, $85 \%$ ee), although a slight decrease of ee was observed. From this result, it is expected that this HDA reaction using our two catalyst components system may be useful for practical aspect.

\subsection{Reaction mechanism}

Based on the observed highly enantiopurity of the obtained HDA adduct $[2 S, 6 R]-8 \mathbf{a}$ (rt: $92 \%$ ee, $0{ }^{\circ} \mathrm{C}$ : $93 \%$ ee, entries 6 and

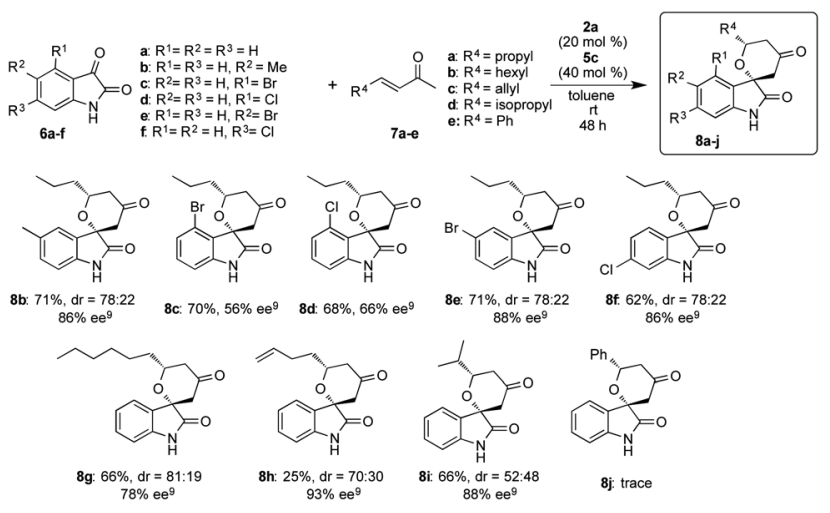

Scheme 3 Substrate scope for asymmetric HDA reaction. 


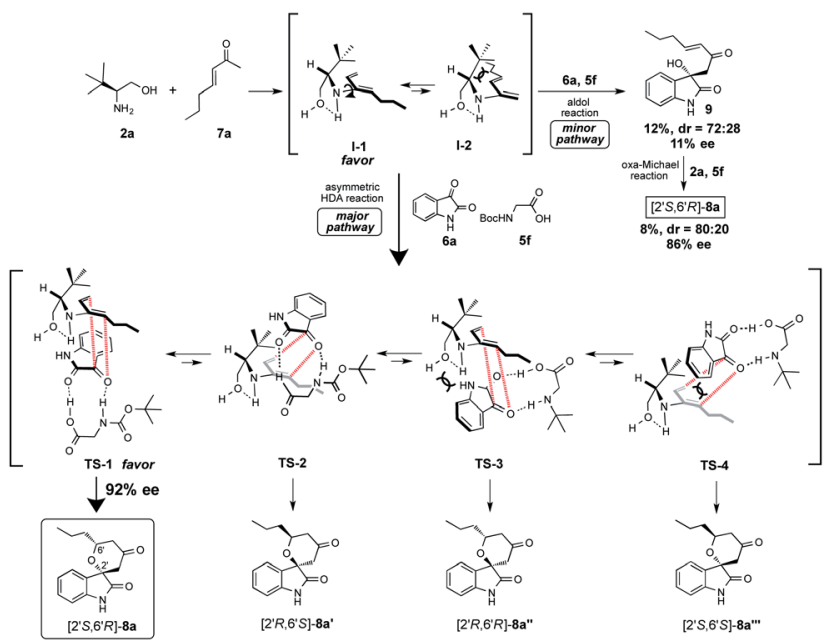

Scheme 4 Plausible reaction course for asymmetric HDA reaction.

25 , Table 1), the model of the enantioselective reaction course was proposed as shown in Scheme 4 . First, the reaction of $\beta$ amino alcohol catalyst $\mathbf{2 a}$ with enone $7 \mathbf{a}$ forms the diene intermediate $\mathbf{I}-\mathbf{1}$ that has less steric interaction of between amino alcohol that is fixed by intramolecular hydrogen bonding and substituted diene parts on generated diene $\mathbf{I}-\mathbf{1}$ than that of intermediate $\mathbf{I}-\mathbf{2}$. Furthermore, isatin $\mathbf{6} \mathbf{a}$ is activated by the two points of hydrogen bonding interactions with $\mathrm{N}$-Boc amino acid co-catalyst 5c. Then, the reaction might proceed through TS-1 to afford 8a that has a less steric interaction between $\mathbf{I - 1}$ and dienophile $6 \mathbf{a}$ than those of TS-2-4 to afford $\mathbf{8} \mathbf{a}^{\prime}-\mathbf{8} \mathbf{a}^{\prime \prime}$ that have more steric interaction between $\mathbf{I - 1}$ and $\mathbf{6 a}$. Thus, diene I-1 might attack stereoselectively from less sterically hindered site of the incoming activated isatin dienophile $6 \mathbf{a}$ to afford [ $2 S, 6 R]$ 8 a with excellent optically purity ( $93 \%$ ee). On the other hand, it is also expected that the formation of adduct $\mathbf{8 a}$ via aldol reaction followed by oxa-Michael addition may be minor pathway based on the chemical yield and enantioselectivity of the obtained aldol product 9 and 8 a was quite low (9: 12\%, $72: 28 \mathrm{dr}$., 16\% ee, 8a: 8\%, 80 : 20 dr., $86 \%$ ee).

\section{Conclusion}

We have developed a simple two catalysts component system consisting of primary $\beta$-amino alcohol $2 \mathbf{a}$ as a catalyst and $N$ protected amino acid $\mathbf{5 c}$ as a co-catalyst for the asymmetric HDA reaction of isatins with enones for the first time. This dual component system showed efficient catalytic activity to afford the chiral spirooxindole-tetrahydropyranones $\mathbf{8 a - j}$ that are efficient synthetic intermediates for many biologically active compounds and drug discovery, in good chemical yields (up to $86 \%$ ) and with enough stereoselectivities (up to 85 : $15 \mathrm{dr}, 95 \%$ ee). In addition, the independent use of simple $\beta$-amino alcohol catalyst 2a also showed good catalytic activity for affording $\mathbf{8 a}$ with an excellent enantioselectivity ( $92 \%$ ee), although chemical yield was low. The modification of the combination of amino alcohols and detailed mechanistic study of this reaction using our catalysts system are in progress.

\section{Experimental}

\subsection{General information}

All reagents and dry solvents were purchased from commercial vendors and used directly without further purification. All reactions were placed in dried sample vials inserted with magnetic beads. Thin-layer chromatography (TLC) was performed on Merck silica gel $60 \mathrm{~F}_{254}$ plates and the analytes were identified under UV light. Flash column chromatography was performed using silica gel pore size $60_{\mathrm{N}}(40-100 \mu \mathrm{m})$. Melting points were recorded with a micro-melting point apparatus. IR spectra were recorded with a JASCO-4100 Fourier transform infrared spectrophotometer. ${ }^{1} \mathrm{H}$ and ${ }^{13} \mathrm{C}$ NMR spectroscopic data were recorded using a JEOL JNM-ECA500 instrument with tetramethyl silane as the internal standard. HPLC data were collected using the TOSOH instrument equipped with (UV-8020, DP-8020, and SD-8022) detectors using CHIRALPAK IB column. Optical rotations were recorded using a JASCO DIP-360 digital polarimeter. High-resolution mass spectrometry (HRMS) data were collected by electron impact (EI) modes using Hitachi RMG-GMG and JEOL JNX-DX303 sector instruments.

\subsection{General procedure for the hetero Diels-Alder (HDA) reaction of isatins (6a-f) with enones (7a-e)}

To a solution of the corresponding isatins $\mathbf{6 a}-\mathbf{f}(0.2 \mathrm{mmol}, 1 \mathrm{eq}$. and enones $7 \mathbf{a}-\mathbf{e}(0.8 \mathrm{mmol}, 4$ eq.) in anhydrous toluene $(0.3$ $\mathrm{mL}$ ) were added catalysts $2 \mathrm{a}-\mathbf{e}$ or $\mathbf{4 a}-\mathbf{e}(0.04 \mathrm{mmol}, 20 \mathrm{~mol} \%)$ and co-catalysts $5 \mathbf{a}-\mathbf{k}(0.08 \mathrm{mmol}, 40 \mathrm{~mol} \%)$ at room temperature and the mixture were stirred at that temperature for $48 \mathrm{~h}$. The mixture was purified by flash column chromatography $\left(\mathrm{SiO}_{2}\right.$ : hexane/ethyl acetate, $\left.7: 3\right)$ to afford the corresponding major HDA adducts $\mathbf{8 a}-\mathbf{j}$. ${ }^{9}$ The diastereoselectivity (dr) of the obtained HDA adducts were determined by the crude reaction mixture by ${ }^{1} \mathrm{H}$-NMR. ${ }^{9}$ The enantiomeric excess (ee) of $\mathbf{8 a}-\mathbf{j}$ were determined by HPLC (CHIRALPAK-IB, hexane/i-PrOH $=70: 30$, $90: 10$ and $95: 5,1.0 \mathrm{~mL}$ and $\left.0.6 \mathrm{~mL} \min ^{-1}, \lambda=245 \mathrm{~nm}\right){ }^{9}$

\section{Conflicts of interest}

There are no conflicts to declare.

\section{Notes and references}

1 (a) B. Tan, N. R. Candeias and C. F. Barbas, Nat. Chem., 2011, 3, 473; (b) B. D. Horning and D. W. C. MacMillan, J. Am. Chem. Soc., 2013, 135, 6442; (c) T.-P. Gao, J.-B. Lin, X.-Q. Hu and P.-F. Xu, Chem. Commun., 2014, 50, 8934; (d) H. Huang, M. Bihani and C.-G. Zhao, Org. Biomol. Chem., 2016, 14, 1755; (e) D. G. Hall, T. Rybak and T. Verdelet, Acc. Chem. Res., 2016, 49, 2489; (f) M. Uroos, P. Pitt, L. M. Harwood, W. Lewis, A. J. Blake and C. J. Hayes, Org. Biomol. Chem., 2017, 15, 8523; $(g)$ B. Yang and S. Gao, Chem. Soc. Rev., 2018, 47, 7926; (h) G.-L. Mei and F. Shi, Chem. Commun., 2018, 54, 6607.

2 A. Fensome, W. R. Adams, A. L. Adams, T. J. Berrodin, J. Cohen, C. Huselton, A. Illenberger, J. C. Kern, 
V. A. Hudak, M. A. Marella, E. G. Melenski, C. C. McComas, C. A. Mugford, O. D. Slayden, M. Yudt, Z. Zhang, P. Zhang, Y. Zhu, R. C. Winneker and J. E. Wrobel, J. Med. Chem., 2008, 51, 1861.

3 G. Kumari, Nutan, M. Modi, S. K. Gupta and R. K. Singh, Eur. J. Med. Chem., 2011, 46, 1181.

4 (a) J.-J. Liu and Z. Zhang, US Pat., US2008114013A1, 2008; (b) H.-L. Cui and F. Tanaka, US Pat., US9309261B2, 2014; (c) K. Ding, Y. Lu, Z. Nikolovska-Coleska, S. Qiu, Y. Ding, W. Gao, J. Stuckey, K. Krajewski, P. P. Roller, Y. Tomita, D. A. Parrish, J. R. Deschamps and S. Wang, J. Am. Chem. Soc., 2005, 127, 10130; (d) K. Ding, Y. Lu, Z. NikolovskaColeska, G. Wang, S. Qiu, S. Shangary, W. Gao, D. Qin, J. Stuckey, K. Krajewski, P. P. Roller and S. Wang, J. Med. Chem., 2006, 49, 3432; (e) Q. Ding, J.-J. Liu and Z. Zhang, WO2007104714A1, 2007.

5 V. V. Vintonyak, K. Warburg, H. Kruse, S. Grimme, K. Hubel, D. Rauh and H. Waldmann, Angew. Chem., Int. Ed., 2010, 49, 5902.

6 (a) M. Rottmann, C. McNamara, B. K. Yeung, M. C. Lee, B. Zou, B. Russell, P. Seitz, D. M. Plouffe, N. V. Dharia, J. Tan, S. B. Cohen, K. R. Spencer, G. E. Gonzalez-Paez, S. B. Lakshminarayana, A. Goh, R. Suwanarusk, T. Jegla, E. K. Schmitt, H. P. Beck, R. Brun, F. Nosten, L. Renia, V. Dartois, T. H. Keller, D. A. Fidock, E. A. Winzeler and T. T. Diagana, Science, 2010, 329, 1175; (b) B. K. Yeung, B. Zou, M. Rottmann, S. B. Lakshminarayana, S. H. Ang, S. Y. Leong, J. Tan, J. Wong, S. Keller-Maerki, C. Fischli, A. Goh, E. K. Schmitt, P. Krastel, E. Francotte, K. Kuhen, D. Plouffe, K. Henson, T. Wagner, E. A. Winzeler, F. Petersen, R. Brun, V. Dartois, T. T. Diagana and T. H. Keller, J. Med. Chem., 2010, 53, 5155.
7 (a) G. Bencivenni, L.-Y. Wu, A. Mazzanti, B. Giannichi, F. Pesciaioli, M.-P. Song, G. Bartoli and P. Melchiorre, Angew. Chem., Int. Ed., 2009, 48, 7200; (b) L.-L. Wang, L. Peng, J.-F. Bai, Q.-C. Huang, X.-Y. Xu and K.-X. Wang, Chem. Commun., 2010, 46, 8064; (c) Y.-B. Lan, H. Zhao, Z.-M. Liu, J.-C. Tao and X.-W. Wang, Org. Lett., 2011, 13, 4866; (d) G. S. Singh and Z. Y. Desta, Chem. Rev., 2012, 112, 6104.

8 (a) V. Gouverneur and M. Reiter, Chem.-Eur. J., 2005, 11, 5806; (b) H. Pellissier, Tetrahedron, 2009, 65, 2839-2877; (c) V. E-Lux, K. Kumar and H. Waldmann, Angew. Chem., Int. Ed., 2014, 53, 2; (d) M. M. Heravi, T. Ahmadi, M. Ghavidel, B. Heidari and H. Hamidi, RSC Adv., 2015, 5, 101999; (e) S. Jayakumar, K. Louven, C. Strohmann and K. Kumar, Angew. Chem., Int. Ed., 2017, 56, 15945; $(f)$ D. Zhang and F. Tanaka, RSC Adv., 2016, 6, 61454.

9 (a) H.-L. Cui and F. Tanaka, Chem. - Eur. J., 2013, 19, 6213; (b) H.-L. Cui, P. V. Chouthaiwale, F. Yin and F. Tanaka, Asian J. Org. Chem., 2016, 5, 153; (c) H.-L. Cui, P. V. Chouthaiwale, F. Yin and F. Tanaka, Org. Biomol. Chem., 2016, 14, 1777.

10 (a) Y. Kohari, Y. Okuyama, E. Kwon, T. Furuyama, N. Kobayashi, T. Otuki, J. Kumagai, C. Seki, K. Uwai, G. Dai, T. Iwasa and H. Nakano, J. Org. Chem., 2014, 79, 9500; (b) T. Takahashi, U. V. Subba Reddy, Y. Kohari, C. Seki, T. Furuyama, N. Kobayashi, Y. Okuyama, E. Kwon, K. Uwai, M. Tokiwa, M. Takeshita and H. Nakano, Tetrahedron Lett., 2016, 57, 5771; (c) U. V. Subba Reddy, M. Chennapuram, C. Seki, E. Kwon, Y. Okuyama and H. Nakano, Eur. J. Org. Chem., 2016, 24, 4124; (d) H. Nakano, I. A. Owolabi, M. Chennapuram, Y. Okuyama, E. Kwon, C. Seki, M. Tokiwa and M. Takeshita, Heterocycles, 2018, 97, 647. 